\title{
De la correspondencia al relato del viaje americano de Humboldt
}

\section{From correspondence to American travel writing of Humboldt}

\author{
Cristina G. DE Uriarte \\ Universidad de La Laguna \\ curiarte@ull.edu.es
}

\begin{abstract}
Based on the historic relationship of the American travel and the letters written during the expedition, we will make an approach to the way Humboldt faces the writing of his 'itinerary' and we will observe how the passing of time affects this recollection. We will see that, in addition to the indispensable information selection process, there is and evident concern about updating the scientific contents and an undeniable desire to please the reader.
\end{abstract}

\section{Key-words}

Humboldt, French travel writing, the XIX century.

\begin{abstract}
Résumé
À partir de la relation historique de son voyage américain et des lettres écrites pendant cette expédition, notre but est de voir comment Humboldt envisage la rédaction de son "itinéraire". Nous constaterons, ainsi, comment cette rémémoration est influencée par le passage du temps. Nous verrons, donc, que, en plus de l'incontournable procès de sélection de l'information, il existe le souci d'actualisation des contenus scientifiques et l'indéniable désir de plaire le lecteur.
\end{abstract}

\section{Mots clés}

Humboldt, récits de voyage français, $\mathrm{XIX}^{\mathrm{e}}$ siècle. 


\section{Introducción}

“Douze années se sont écoulées depuis que je quittai l'Europe pour parcourir l'intérieur du nouveau continent". Con estas palabras Humboldt ${ }^{1}$ (1814: 1) inicia la introducción de la relación histórica de su viaje americano, efectuado entre 1799 y 1804 . Fechada en febrero de 1812, las casi 40 páginas que preceden el relato dan cuenta, entre otras cosas, de la cuidada preparación de esta empresa de carácter privado ${ }^{2}$, del imprescindible apoyo del gobierno español para ejecutarla ${ }^{3}$ junto al botánico Aimé Bonpland -para el que siempre tiene palabras de afecto- o del número considerable de observaciones realizadas y cuya publicación "sembloit offrir quelque intérêt pour l'histoire des peuples et la connoissance de la nature" (1814: 2). Todo ello compensa, sin lugar a dudas, dificultades tales como las constantes trabas para publicar la obra, pero, sobre todo, el hambre, las enfermedades, los peligros en tierra firme o en el mar y las penalidades que rodean a una empresa de estas características.

Aunque, como el propio científico confiesa (1814: 7), no logra todos sus objetivos, es incuestionable la relevancia de los resultados de esta expedición -la más ambiciosa jamás emprendida por un particular- por territorios casi desconocidos entonces en Europa ${ }^{4}$. La edición príncipe del Voyage aux régions équinoxiales du nouveau continent, fait en 1799, 1800, 1801, 1802, 1803 et 1804 consta de 30 volúmenes -escritos en francés, excepto algunos de botánica, en latín- editados en París entre 1805 y 1836.

Siguiendo el modelo tradicional del relato de viajes científico, el contenido está orga-

1 Alejandro de Humboldt, Alexandre de Humboldt o Alexander von Humboldt son las distintas versiones de su firma que utiliza según se encuentre en países de habla hispana, en Francia o en Alemania.

2 Financiada gracias a la herencia de su madre, los planes iniciales se ven modificados en diferentes ocasiones. Tras haber obtenido el permiso para embarcar en una de las corbetas de la campaña del capitán Baudin a tierras australes, la reanudación de la guerra con Austria y la falta de fondos llevan al Directorio a posponer la expedición con carácter indefinido -si bien, finalmente, se lleva a cabo entre 1800 y $1803-$. Humboldt intenta entonces, sin éxito, realizar el antiguo proyecto de viajar a Egipto, por lo que se desplaza, junto a Bonpland, a España.

3 Gracias a los salvoconductos que les proporciona Carlos IV para explorar las provincias americanas que se encontraban bajo dominio español, los dos científicos embarcan en La Coruña el 5 de junio de 1799 en la corbeta Pizarro. Tras la escala en Tenerife, del 17 al 25 de junio, arriban a Cumaná poco después, concretamente, el 16 de julio.

4 El número de investigaciones sobre la figura de este viajero políglota -que se comunica con fluidez en alemán, francés o español-, sus aportaciones científicas o los problemas de edición de sus innumerables escritos es elevadísimo. Por lo que concierne a este viaje, la mayor parte de los trabajos se centran, como es lógico, en la estancia en el continente americano. Su número y calidad es tan elevado que un intento de selección por nuestra parte resultaría arbitrario. No ocurre lo mismo con el paso por España, antes del inicio de la travesía o durante la primera escala en el archipiélago canario, que ha sido abordado en menor medida, aunque con igual rigor, por parte de Cioranescu (1978), Puig-Samper (1999), Bourguet (2003) o Prüfer Leske (2014), entre otros. Por otra parte, a lo largo de 2019, año en el que se celebra el 250 aniversario del nacimiento de Alexander von Humboldt, tendrán lugar diferentes conmemoraciones y exposiciones. Una de ellas es la que reúne sus cerca de 4.000 páginas de anotaciones, dibujos o esbozos recogidos en cartas y diarios y que se mostrarán en el futuro Humboldt Forum en Berlín, que toma su nombre de los hermanos Alexander y Wilhelm, reconocido lingüista. 
nizado en función de la disciplina abordada. Así, a la relación histórica del viaje -que consta de tres tomos publicados en 1814, 1819 y 1825-y el atlas "pittoresque", Vues des Cordillères et Monumens des peuples indigènes du nouveau continent (1810), se suman los volúmenes de botánica, geografía, astronomía o zoología y anatomía comparada. Las mediciones, descripciones y análisis se completan con el conjunto formado por más de 1.400 ilustraciones -en negro y en color- de plantas, animales, mapas o monumentos. De los bocetos se ocupan Humboldt y Bonpland, pues en esta expedición no les acompaña un dibujante profesional. A pesar del poco tiempo que permanecen en un mismo lugar, estos esbozos son el germen de los extraordinarios óleos y acuarelas realizados posteriormente por artistas europeos, a partir de los cuales se elaboran los grabados en cobre cuya ejecución supervisa personalmente el científico alemán ${ }^{5}$ :

J'ai taché de donner la plus grande exactitude à la représentation des objets qu'offrent ces gravures. [...] Si quelques-unes sont moins parfaites que les connoisseurs ne pourroient le désirer, cette imperfection ne doit pas être attribuée aux artistes chargés, sous mes yeux, de l'exécution de mon ouvrage, mais aux esquisses que j'ai faites sur les lieux dans des circonstances souvent très pénibles (1810: V).

Curiosamente, muchos de ellos son los primeros, e incluso únicos, testimonios visuales de algunos aspectos de la realidad americana. Él mismo lamenta (1810: II) que los relatos de los primeros viajeros españoles a América no incluyeran imágenes que proporcionaran una idea exacta de los monumentos, algunos de los cuales desaparecerían luego o quedarían convertidos en ruinas debido al fanatismo o la despreocupación. En opinión de Holl (2003: 157), buena parte del éxito de esta expedición reside en la flexibilidad y capacidad de improvisación que le permitían el no disponer de su propia nave, ni de tripulación.

Una parte de los resultados de esta campaña se da a conocer antes de la publicación del Voyage en forma de memorias e informes que el propio Humboldt elabora para diferentes sociedades científicas. Un ejemplo es el texto, en francés, de finales de junio de 1804 -realizado durante la estancia en los Estados Unidos y antes del regreso a Francia- para la American Philosophical Society de Filadelfia. Redactado en tercera persona, se trata de un testimonio de gran valor, pues constituye la primera narración completa del itinerario de la exploración 6 .

Pocas semanas después de su vuelta a Europa, Humboldt comienza la lectura de una Relation abrégée de su viaje en el Institut de France en París. A partir de este documento -que, aparentemente, no se ha conservado- y de la correspondencia pública y particular de Humboldt, el físico y naturalista Delamétherie escribe Notice d'un voyage aux tropiques, executé par MM. Humboldt et Bonpland en 1799, 1800, 1801, 1802, 1803

5 Para más detalles sobre la conexión entre ciencia y arte en Humboldt, vid., Holl (2003: 157-168) y Garrido Moreno (2018).

6 La traducción española puede consultarse en Puig-Samper y Rebok (2002). 
et 1804. Confeccionado con la ayuda de cartas ya desaparecidas, coincide en gran medida con el entregado a la American Philosophical Society cuyo original se conserva en los Estados Unidos. Solo de la expedición americana se contabilizan 69 trabajos -elaborados hasta 1870 , en francés, alemán, latín, español, holandés y polaco- de un total de 636, que incluyen libros, artículos, traducciones o reediciones correspondientes al periodo 17891870 (Minguet, 1985: 9, t. I).

La redacción de numerosísimos cuadernos ${ }^{7}$ y cartas es una constante estrechamente relacionada con la intensa actividad científica que Humboldt desarrolla a lo largo de su vida: "Mettre le monde en notes fut chez lui une manière de vivre" (Bourguet, 2006: 20). Su intrincada caligrafía -que él mismo define como "diabolicomicroscopique" - por un lado, y la abundante información que contienen sus manuscritos, por otro, han dificultado enormemente su consulta hasta fechas recientes. Margot Faak, colaboradora del Centro de Investigación Alexander von Humboldt de la Academia de Ciencias de Berlín, inicia en 1982 la edición de los trece diarios de la expedición americana y la concluye en $2000^{8}$. Estas páginas contienen -junto a descripciones, anotaciones y toda clase de aclaraciones científicas- añadidos, correcciones y apéndices biográficos en los que el científico trabaja de forma incansable hasta su muerte.

En cuanto a la correspondencia, que algunos estudiosos calculan en más de 50.000 cartas $^{9}$, su divulgación plantea, igualmente, serios problemas. Escrita principalmente en francés y alemán, pero también en español, desde cualquier lugar del mundo a destinatarios en distintos países, una parte se ha perdido y otra no ha sido identificada.

Dado que la crónica del viaje solo recoge una etapa de la exploración, iniciada en La Coruña en junio de 1799, y se interrumpe en Cartagena de Indias el 20 de abril de 1801, la lectura de documentos complementarios resulta, lógicamente, de gran valor. Aun cuando hay largos periodos de tiempo en los que no se tiene noticias de Humboldt o estas son escasas ${ }^{10}$, las denominadas cartas americanas ${ }^{11}$ nos permiten acceder a algunas lagunas informativas del relato y conocer aspectos tales como la continuación del periplo, el regreso a Francia o

7 Para más información sobre esta cuestión, vid., entre otros, Puig-Samper (2010) y Ette (2015). En el primero de estos trabajos leemos, entre otras cosas, que Humboldt utiliza cuadernos de diferentes colores para las distintas disciplinas y combina en la escritura el francés y el alemán. Ette, por su parte, analiza, entre otros aspectos, la vinculación entre la escritura de los diarios y los elementos visuales que caracterizan a Humboldt, quien suele estar representado escribiendo en un cuaderno apoyado en sus rodillas.

8 Alexander von Humboldt. Reise durch Venezuela. Auswahl aus den amerikanischen Reisetagebüchern (Berlín, Akademie Verlag). Los manuscritos de estos diarios, redactados en alemán, francés y español, se conservan en la Biblioteca nacional de Berlín y, desde 2017, están disponibles en línea.

9 Y de la que tenemos constancia gracias a los trabajos de Rocquette (1865), Hamy (1905) o Minguet (1980), entre otros.

10 Esta correspondencia llega a Europa a través de los barcos que zarpan con destino al continente y que no siempre logran tomar puerto. Esto explica la costumbre de copiar varias veces la misma carta, algo que no es del agrado de Humboldt.

11 Para este trabajo hemos utilizado la edición de Hamy (1905) que incluye, junto a 63 cartas que comprenden el periodo del 3 de abril de 1798 al 12 de febrero de 1807, varios apéndices y la Notice de Delamétherie, ya mencionada. 
ciertos detalles acerca de la edición de la obra. Como es fácil suponer, el autor se expresa aquí más libremente y encontramos informaciones y comentarios que no son luego íntegramente reproducidos ${ }^{12}$.

Si el análisis de las aportaciones a la ciencia de este viajero e investigador meticuloso, considerado el segundo descubridor de América, sigue despertando interés hoy en día, el proceso de escritura de su relato ha llamado algo menos la atención. A partir de la comparación de la relación histórica, publicada años después de concluida la expedición, y de las cartas redactadas durante su desarrollo, nos acercaremos a la manera en que Humboldt se enfrenta a la redacción de su "itinerario" y comprobaremos cómo afecta el paso del tiempo en esta rememoración. En este proceso de reescritura del viaje, esto es, escritura de algo ya redactado, Humboldt prefiere alejarse de la repetición innecesaria y opta por suprimir, ampliar o corregir lo ya escrito. Desde esta perspectiva, a la evidente preocupación por actualizar los contenidos científicos se une un innegable deseo de agradar al lector. Mientras las cartas representan la inmediatez y la frescura de las emociones y las opiniones, en el relato el autor puede optar por revivir, tamizar o alterar los recuerdos.

\section{La publicación del viaje americano}

Como ya hemos señalado, la relación histórica del Voyage aux régions équinoxiales comprende tres volúmenes ${ }^{13}$, el primero de los cuales ve la luz diez años después de la finalización del viaje y después, también, de la publicación de otros volúmenes de esta obra y de diferentes textos relacionados con la exploración. Aunque la narración se detiene a comienzos de 1801, muchos de los contenidos relativos a los territorios visitados con posterioridad -Nueva Granada (Colombia actual), Audiencia de Quito (Ecuador), Perú, México, Cuba (adonde se desplaza en dos ocasiones) y, finalmente, los Estados Unidos- figuran, bien en obras especialmente consagradas a ellos -Essai Politique sur le Royaume de la Nouvelle Espagne (1811) y Essai Politique sur l'île de Cuba (1826) -, bien repartidos en distintos trabajos.

Son conocidas las reticencias de Humboldt -que él mismo califica de "extrema repugnancia" (1814: 29) - a publicar un relato de viajes al uso, donde la cronología de los acontecimientos domina la narración y abundan las aventuras y los detalles anecdóticos, entremezclados con algunas consideraciones históricas o científicas. "J'avois quitté l'Europe dans la ferme résolution de ne pas écrire ce que l'on est convenu d'appeler la relation historique d'un voyage, mais de publier le fruit de mes recherches dans des ouvrages purement descriptifs"

12 A modo de ejemplo, la carta que Humboldt escribe desde Aranjuez el 20 de abril de 1799 al botánico Willdenow completa la información de la introducción de la relación histórica, aportando detalles ausentes en el relato.

13 A pesar de que el manuscrito del cuarto y último volumen ya está listo y ha empezado a imprimirse, Humboldt decide destruirlo. Minguet sostiene que la narración de esta parte de la exploración habría obligado a su autor a mencionar y justificar comprometidas decisiones personales relacionadas con la elección del científico que le acompañaría durante una parte del itinerario americano (1985: 122). 
(1814: 28). Para ello realiza toda clase de anotaciones y describe sus primeras impresiones de la naturaleza y de los hombres sin planteamiento editorial alguno:

[...] je n'avois d'autre but que de consérver quelques-unes de ces idées éparses qui se préséntent à un physicien, dont preque toute la vie se passe en plein air, de réunir provisoirement une multitude de faits que je n'avois pas le temps de classer, et de décrire les premières impressions agréables ou pénibles que je recevois de la nature et des hommes. J'étois bien éloigné alors de croire que ces pages écrites avec précipitation feroient un jour la base d'un ouvrage étendu que j'offrirois au public (1814: 29).

De regreso a Europa, los obstáculos para publicar algunas de las observaciones son determinantes en su cambio de opinión y en su decisión de escribir la relación de su viaje (1814: 29). Como manifiesta en repetidas ocasiones, su propósito no es presentar una secuencia de los hechos, sino exponer las relaciones que estos establecen entre sí. En la brevísima carta dirigida al mineralogista austriaco De Moll, y que reproducimos a continuación, leemos:

Dans peu d'heures nous doublerons le cap Finistère. Je collectionnerai des plantes et des fossiles, et je pourrai faire des observations astronomiques avec des instrumens excellents; j'analyserai l'air à l'aide de la chimie. Mais tout cela n'est pas le but principal de mon voyage. Mon attention ne doit jamais perdre de vue l'harmonie des forces concurrentes, l'influence de l'univers inanimé sur le règne animal et végétal [...] (1905: 18).

La extensión excesiva de los capítulos o la falta de claridad expositiva son algunos de los aspectos que preocupan a Humboldt y que le llevan a plantearse en distintos momentos la distribución del contenido. Alejándose de la estructura habitual del diario de viajes, desde un principio tiene previsto publicar su trabajo en varios volúmenes, pues es la forma más adecuada para un público previsiblemente heterogéneo. Así lo manifiesta en la carta que escribe a Willdenow desde La Habana el 21 de febrero de 1801 (1905: 108) y, posteriormente, en la introducción de la relación histórica:

\begin{abstract}
Nos recherches ayant été dirigées vers des objets très-variés, nous n'avons pu en présenter les résultats sous la forme ordinaire d'un journal: nous les avons consignés dans plusieurs ouvrages distincts, rédiges dans le même esprit, et liés entre eux par la nature des phénomènes qui y sont discutés. Ce genre de rédaction, qui fait découvrir plus facilement l'imperfection des travaux partiels, n'est pas avantageux pour l'amour propre du voyageur; mais il est préférable pour tout ce qui a rapport aux sciences physiques et mathématiques, parce que les différentes branchés de ces sciences sont rarement cultivées par la même classe de lecteurs (1814: 2).
\end{abstract}

Redactado cuando ya se han publicado más de dos tercios del conjunto, el contenido del prefacio es el tradicional ${ }^{14}$. Entre otras cosas, conocemos las razones del viaje y el método

14 Sobre las características de la introducción en el relato de viajes, vid., G. de Uriarte (2018). 
de trabajo seguido, las dificultades para el transporte y conservación de las colecciones o los resultados obtenidos. Asimismo, la aceptación de posibles errores, la rememoración de las adversidades y los sacrificios, pero también del apoyo recibido ${ }^{15}$ encuentran un hueco en este apartado, en el que no falta la preocupación por la evolución de la situación política en los países visitados.

No obstante, si bien los contenidos anunciados al comienzo del primer capítulo -preparativos, instrumentos, salida de España y escala en las islas Canarias-son, igualmente, los habituales, en él leemos otras informaciones más propias de la introducción. Concretamente, nos referimos a la queja por los obstáculos iniciales para llevar a cabo la empresa, algo que, reitera, no habría sucedido si se hubiera tratado de una campaña estata ${ }^{16}$, la inclinación temprana de Humboldt por la ciencia y los viajes o la denuncia, en una nota a pie de página, de la publicación del Voyage autour du monde et dans l'Amérique méridionale en 6 volúmenes con su nombre y elaborado a partir de información suya (1814: 40).

Son constantes en sus páginas la insistencia en la fidelidad y exhaustividad de lo consignado por escrito; un acto realizado, por lo general, a la vista de las cosas -“cette relation ayant été rédigée d'après les notes que j'ai écrites sur les lieux" (1814: 34) - que, posteriormente, pasa por el tamiz de la reflexión y la verificación. Recordemos que la atención del viajero a comienzos del siglo XIX no se dirige únicamente hacia los objetos, sino también hacia las condiciones en las que se efectúan las observaciones. De ahí la importancia de recoger en los cuadernos las anotaciones adecuadas que serán luego analizadas ${ }^{17}$, cuando el recurso a la memoria se revele insuficiente para obtener respuestas correctas: "Rien ne me préoccupe dans mon voyage autour du monde aussi obstinément que de sauver mes manuscrits et mes herbiers" (1905: 107).

Ette llama la atención sobre el hecho de que existen muchos pasajes de los diarios -de los que solo se ha conservado una parte- que fueron desarrollados más tarde: "Humboldt siempre dejaba muchas páginas en blanco, para volver a llenarlas en un momento posterior, ya fuera con una representación sinóptica o con un resumen temáticamente centrado" (2015: 42). Sabemos, además, que la escritura de estos diarios se interrumpe cuando, por ejemplo, el científico se encuentra en una ciudad o cuando otras ocupaciones de mayor importancia

15 A menudo Humboldt expresa su gratitud al gobierno español por poder llevar a cabo esta empresa en un lugar en el que se siente inmensamente feliz. "Plus que je vis dans les colonies espagnoles et plus je m'y plais" o "Je ne puis assez te répéter combien je me trouve heureux dans cette partie du monde" son solo una pequeñísima muestra de su estado de ánimo, que no se ve afectado por el paso del tiempo y las penalidades. Respecto a aquellos que afirman que está a las órdenes de la monarquía española, de la que probablemente reciba un puesto en el Consejo de Indias, confiesa que no solo valora enormemente su independencia de cualquier gobierno, sino que: "Une vie, commencée comme la mienne, est faite pour l'action" (1905: 113).

16 De la expresión de su malestar destacamos la siguiente frase: "Peu de particuliers ont eu à combattre des difficultés plus nombreuses que celles qui se sont présentées à moi avant mon départ pour l'Amérique espagnole; j'aurois préféré n'en point faire le récit, et commencer cette relation par le voyage à la cime du Pic de Ténériffe' (1814: 40).

17 Y que subrayan frases del tipo "Je vais transcrire de mon journal un fait qui a eu lieu pendant la maladie de M. Bonpland" (1819: 640) o "Une faute de chiffres dans mon journal a rendu la longitude incertaine" (1819: 496). 
acaparan su atención: “Au milieu d'une nature imposante, vivement occupé des phénomènes qu'elle offre à chaque pas, le voyageur est peu tenté de consigner dans ses journaux ce qui a rapport à lui-même et aux détails minutieux de la vie" (1814: 28).

Por lo que concierne a la autoría de la obra, aunque está firmada por Humboldt y Bonpland, lo cierto es que el principal autor del Voyage es el primero. A excepción de la participación puntual de algunos científicos, Bonpland colabora únicamente en la parte botánica. Es a él a quien Humboldt atribuye su éxito, por lo que, en reconocimiento a esta labor, solicita al Muséum national d'Histoire naturelle que le nombre naturalista viajero del Jardin des Plantes ${ }^{18}$.

Respecto a la edición, conocemos algunos pormenores sobre su proceso o sobre las relaciones, no siempre fáciles, con los editores, especialmente a través de la correspondencia. Así, en la larga carta dirigida a Pictet ${ }^{19}$, fechada el 1 de abril de 1805, informa a su amigo, entre otras cosas, del estado de la impresión y publicación, pero, sobre todo, muestra su preocupación acerca de la edición y comercialización de la versión inglesa, autorizándole a cambiar "tout ce qui vous paraît trop local, trop en faveur de la France, trop peu chrétien, etc." (1905: 199). Se da la circunstancia de que ya en 1801, en el transcurso de la expedición, da una serie de indicaciones a su amigo y mentor Willdenow sobre la edición de su trabajo en el caso de que falleciera antes de poder ocuparse personalmente de ella:

Si je devais mourir, Delambre éditera mes manuscrits astronomiques; V. Scheerer, les manuscrits physiques et chimiques; Freiesleben ou Buch, mes travaux géognostiques; Blumenbach, ceux qui traitent de la zoologie, et toi, mon cher (je l'espère au moins), mes études botaniques, en mon nom, et au nom de Bonpland. Mon frère enverra à chacun les manuscrits (1905: 109).

El precio final de la edición monumental del viaje americano resulta tan elevado -no en vano se trata de la publicación científica más voluminosa y cara de la historia jamás editada y financiada por un particular (Holl, 2003: 32) - que Humboldt decide imprimir, paralelamente, ediciones más modestas y asequibles a un mayor número de lectores que se traducen, igualmente, a varios idiomas.

Con esta obra su autor desarrolla una forma de escritura del viaje en la que renueva algunas de sus reglas. Heredero del espíritu enciclopedista, su curiosidad no tiene límites, como tampoco su rigor y exceso de celo que le llevan, por ejemplo, a confesar que descono-

18 La respuesta oficial rechaza la petición basándose en el elevado coste económico que conlleva dicho nombramiento. Sí se le concede una pensión, un procedimiento que es, por otra parte, el usual con otros viajeros.

19 Físico y profesor en Ginebra, Marc-Auguste Pictet será el encargado de traducir, anotar y editar la obra en Gran Bretaña. Para ello Humboldt le envía "Mes confessions" (1805) con la carta del 3 de enero de 1806 y con la indicación "à lire et à me renvoyer un jour" (el documento puede consultarse en Hamy, 1905: 236-244). Al final del texto le da unas instrucciones respecto a su nombre: prefiere que se refiera a él como M. Humboldt o M. Alexandre Humboldt, que suena, en su opinión, más inglés. En cuanto a su título de barón, pide que se indique una única vez. De las traducciones al alemán y español del Voyage se ocupa el propio Humboldt. 
ce la temperatura exacta de unos manantiales de agua caliente (1825: 41), que ignora a qué género pertenece la quina de Cumaná (1825: 101) o que, contrariamente a lo divulgado, no llega a la cima del Chimborazo, aunque sí logra subir con sus instrumentos hasta un punto jamás alcanzado (1905: 172). Recordemos que por aquel entonces el Chimborazo estaba considerado la cima más elevada del planeta y Humboldt, el hombre que la había escalado.

\section{La reescritura de la experiencia}

En todo viaje es posible distinguir varias temporalidades: un tiempo previo, durante el cual se elaboran hipótesis y expectativas y se procede a la preparación de la empresa, y un tiempo presente en el que tiene lugar el desplazamiento, que incluye, a su vez, un pasado -pues se intenta realizar lo programado- y un futuro -hacia el que se proyectan los planteamientos iniciales-. Concluida la expedición, comienza la fase del balance final y de la rememoración y escritura del periplo. En este estadio el viajero puede optar entre la fidelidad a lo vivido, ignorando el paso del tiempo, o la aceptación de su influencia, adaptando lo ocurrido a la actualidad. Esta reescritura de la experiencia, entendida en su sentido estricto de volver a escribir algo ya escrito introduciendo cambios, es innegable en el caso que nos ocupa, como tendremos ocasión de comprobar.

Ahora bien, desde la nota fielmente reconstruida hasta aquella que constituye un mero punto de partida que se va completando hasta alcanzar el presente, existen fórmulas intermedias. Hay que tener en cuenta, además, que el momento de la toma de notas o de la redacción de la correspondencia difiere del de su lectura, que está condicionada por la naturaleza del lector, bien sea este el propio viajero u otra persona, familiarizada o no con lo narrado. Como veremos a continuación, si determinados pasajes de los textos de Humboldt son particularmente emotivos, otros poseen un marcado carácter informativo y utilitario.

El relato de viajes científico, y la Relation historique no es una excepción, sigue la cronología del desplazamiento y con ella las alusiones al calendario o a la hora exacta en la que se llevan a cabo las diferentes mediciones. Unas veces las referencias temporales son rápidas -en unas líneas se pueden resumir meses- o imprecisas -"Nous quittâmes Madrid vers le milieu du mois de mai. Nous traversâmes une partie de la vieille Castille, le royaume de Léon et la Galice, et nous nous rendîmes à la Corogne, où nous devions nous embarquer pour l'ile de Cuba" (1814: 48)-; otras, en cambio, recuperan el detalle de lo sucedido y, con ello, las emociones.

Desde este punto de vista, uno de los momentos cruciales es siempre el de la partida al que se añade, en esta ocasión, la intención, finalmente frustrada, de unirse a la campaña de Baudin ${ }^{20}$. A lo largo de algo más de una página Humboldt no solo rememora, quince años después, las sensaciones del inicio de la aventura -"Le moment où, pour la première fois,

20 Ya señalamos que dicha expedición había sido pospuesta sin fecha. Humboldt contó siempre con incorporarse a ella en cuanto las condiciones lo permitieran. 
on quitte l'Europe, a quelque chose d'imposant" (1814: 56) -, sino, también, el cambio de planes, que resulta determinante en el desarrollo de la expedición y sus resultados. Aunque lo cierto es que Baudin pasa por el cabo de Buena Esperanza, la información errónea de un periodista lleva a Humboldt a fletar una pequeña embarcación para dirigirse al sur del continente americano en el convencimiento de que el capitán sigue la ruta prevista por el cabo de Hornos: "Je ne me rappelle pas sans regret une expédition qui est liée à plusieurs événements de ma vie" (1814: 56).

Otros episodios especialmente intensos y, por ello, inolvidables, son aquellos en los que la vida peligra. El suceso más grave relatado es el del joven asturiano que fallece a causa de unas fiebres contraídas durante la travesía desde las islas Canarias hasta Cumaná. Hijo único y huérfano de padre, su madre le obliga a embarcar para buscar fortuna en Cuba donde reside un familiar que disfruta de una posición acomodada. Le acompaña otro muchacho que, sin embargo, no enferma : “C'étoit un spectacle déchirant que de voir celui qui survivoit à son ami, s'abandonner à une douleur profonde, et maudire les conseils funestes qui l'avoient jeté dans un climat lointain, où il se trouvoit isolé et sans appui” (1814:215). Este hecho, que no se menciona en las cartas, es descrito en la relación histórica junto a otro en el que el azar, y la ignorancia, salvan la vida de un marinero: como la ubicación de su hamaca impide que pueda recibir los sacramentos, se le transporta a un lugar ventilado cerca de la escotilla donde, para sorpresa de todos, se recupera rápidamente (1814: 210).

Humboldt, por su parte, corre peligro mortal en varias ocasiones. En una de ellas, a finales de marzo de 1801, escapa en un mismo día de los embates del mar y de la violencia de los cimarrones. Encontramos los pormenores de estos acontecimientos en la carta que remite a su hermano el 1 de abril de ese mismo año (1905: 117) y en el tercer volumen de su relato (1825: 542-543). Como él mismo recuerda, esto sucede el domingo de Ramos, curiosamente, la misma fecha en la que un año antes se encontraba, también, en peligro de muerte. Y en otra ocasión, descrita con todo lujo de detalles, evita ser golpeado con una macana, no así su compañero Bonpland:

J'entendis marcher derrière moi; en me tournant, je vis un homme d'une taille élevée, de la couleur des Zambos, et nu jusqu'à la ceinture. Il tenoit presque au-dessus de ma tête une macana, gros bâton de bois de palmier, renflé vers le bout en forme de massue. J'évitai le coup en faisant un saut vers la gauche. M. Bonpland, qui marchoit à ma droite, fut moins heureux. Il avoit aperçu le Zambo plus tard que moi; il reçut au-dessus de la tempe un coup qui l'étendit par terre. Nous nous trouvions seuls, sans armes, à une demi-lieue de toute habitation, dans une vaste plaine bordée par la mer (1814: 508-509) $)^{21}$.

21 Sorprendentemente, el zambo se aleja entonces para intentar coger el sombrero de Bonpland. Cuando nuestros viajeros van hacia él, este echa a correr y cae, momento que aprovecha Bonpland para abordarle. De la posterior pelea, que pudo haber terminado en tragedia, ya que el zambo también llevaba un cuchillo, los científicos salen ilesos gracias a la ayuda de unos comerciantes. 
Resulta evidente que en un viaje de esta naturaleza, de cinco años de duración y por lugares remotos e inhóspitos, el número de anécdotas e incidentes es elevadísimo. No solo su evocación es frecuente en la correspondencia, sino también en la relación, pues, no en vano, estas informaciones constituyen un lugar común del relato de viajes. Además de las menciones a las tormentas o los consejos para calmar el hambre, las referencias a los mosquitos, serpientes de cascabel, caimanes, jaguares o tigres son habituales; unas veces, mitigadas por el paso del tiempo y otras, acompañadas de todo lujo de detalles. Un buen ejemplo nos lo proporciona la larga carta dirigida al gobernador de Venezuela, Manuel Guevara Vasconcelos, el 23 de diciembre de 1800 y de la que destacamos el siguiente párrafo:

C'est ainsi que nous avons terminé un voyage de plus de trois cens lieues, à partir de notre départ de Caracas. Pendant plus de trois mois nous avons dormi sur les bords des fleuves ou dans les forêts les plus touffues, entendant toujours les rugissemens des tigres et nous défendant contre leurs attaques au moyen des feux allumés autour de nos hamacs. L'humidité de l'air faisait pourrir toutes les provisions que nous apportions, en sorte que notre nourriture consistait en bananes, en riz, en poisson et en cassave plus dure qu'une pierre. Les mosquites, les moucherons, une quantité énorme de chiques et de fourmis irritaient notre sang d'une manière d'autant plus insupportable que lorsque nous nous trouvions sur les bords d'une rivière abondante et que nous voulions nous y baigner pour rafraîchir notre corps, nous n'osions pas l'essayer à cause de la férocité des caïmans, des raies, des caribes, des gymnotes, des couleuvres d'eau ou boas (1905: 103).

Pero la rememoración es particularmente dolorosa cuando afecta a personas y cosas ya desaparecidas, bien por causas naturales, bien por el fanatismo que, en ocasiones, guía la conducta de los hombres. Así, a lo largo de dos páginas Humboldt refiere el trágico episodio que da lugar al nombre con que se denomina una montaña, Piedra de la madre ${ }^{22}$, y denuncia las atrocidades realizadas en nombre de un país o una religión:

Je ne me plais point, dans le récit de mes voyages, à m'arrêter à la peinture des malheurs individuels. Ces malheurs sont fréquens partout où il y a des maîtres et des esclaves, des Européens civilisés vivant à côté de peuples abrutis, des prêtres exerçant la plénitude d'un pouvoir arbitraire sur des hommes ignorans et sans défense (1819: 412).

Del mismo modo, el momento de abandonar Caracas, destruida mucho después por un terremoto, concretamente, el 26 de marzo de 1810, cobra un especial dramatismo:

Le souvenir de ce départ est aujourd'hui plus douloureux pour nous qu'il ne l'étoit il y a quelques années. Nos amis ont péri dans les sanglantes révolutions qui, tour à tour, ont donné ou ravi la liberté à ces régions lointaines. La maison que nous avons habitée n'est

22 Se trata de un hecho de extrema crudeza: unos indios arrebatan los hijos a una madre para convertirlos en esclavos. Rota de dolor, intenta por todos los medios recuperarlos y termina azotada en la roca que luego lleva su nombre. 
plus qu'un amas de décombres. D'affreux tremblements de terre ont changé la surface du sol. La ville que j'ai décrite a disparu. Sur ces mêmes lieux, sur cette terre crevassée, s'élève avec lenteur une autre ville (1819: 1).

De naturaleza opuesta, pero de igual intensidad es la emoción que provoca la visión de ciertos paisajes o la vivencia de nuevas experiencias: “Ce n'est en général pas autant la crainte du danger que la nouveauté de la sensation qui frappe si vivement, lorsqu'on vient d'éprouver pour la première fois les effets du tremblement de terre le plus léger" (1814: 515).

Como ya indicamos anteriormente, en otros pasajes la expresión de los sentimientos y de las sensaciones cede el paso a la información. Nos encontramos, entonces, ante un relato reescrito, actualizado, que abarca un periodo más amplio, posterior al de la finalización del viaje. Sabemos que la tardanza en la edición de la Relation historique da lugar a numerosos comentarios por parte de Humboldt, que no es partidario de publicar la crónica de un viaje mucho tiempo después de su término, pues, además de que tanto el lector como el autor pierden el interés por el texto, su posible utilidad puede verse, igualmente, afectada: "Pour l'ordre de la publication il a fallu consulter deux intérêts, l'un de ne pas se nuire à la réputation dans un moment que le public m'honore d'une si grande attention et l'autre de ne pas fatiguer le public par une impatience trop prolongée" (1905: 183).

Desde este punto de vista, la narración del pasado únicamente tiene sentido desde la perspectiva del presente. Entre los numerosos ejemplos destacamos el suplemento que cierra el primer volumen y en el que se mencionan las correcciones efectuadas tras la comparación de los datos de diferentes científicos (1814: 639); las Adiciones del último tomo que contienen tablas y explicaciones diversas o las frecuentes notas a pie de página en las que son contrastados distintos resultados.

A partir del momento en que el viajero entra en contacto con la realidad lleva a cabo un primer proceso de selección de lo que merece ser anotado; dicho criterio es posteriormente confirmado, o no, en la redacción del relato. Esta distancia temporal permite tomar determinadas decisiones relativas al contenido, que puede ser completado, corregido o, simplemente, suprimido. Esto sucede, por ejemplo, cuando antes de partir, y ya en España, Humboldt realiza el trayecto desde Barcelona a Madrid. Durante el camino efectúa una serie de observaciones que publica de manera independiente, pero que, sin embargo, prefiere no reproducir en su narración argumentando que el lugar ha sido visitado "recientemente" por muchos viajeros (1814: 46). Las principales razones esgrimidas para no abordar algún aspecto son, por tanto, su escaso interés (1814: 63) o el deseo de no incurrir en repeticiones:

Comme depuis mon retour en Europe, d'autres voyageurs mon devancé dans la description de quelques parties des côtes qu'ils ont visitées après moi, je dois me borner ici à donner du développement aux observations vers lesquelles leurs études n'étoient point dirigées (1814: 293-294). 
Y algo similar sucede con el documento que obtiene sobre la erupción del volcán canario Chahorra en 1798 y que Humboldt pensaba incluir en su Voyage: "Treize années se sont écoulées depuis cette époque; et M. Bory de Saint-Vincent m'ayant devancé dans la publication de ce mémoire, je renvoie le lecteur à son intéressant Essais sur les îles Fortunées" (1814: 179). Las frecuentes remisiones a otros volúmenes o apartados obedecen, igualmente, al mismo propósito.

En cualquier caso, cabe preguntarse si algunas de las negativas a hablar de un lugar o acontecimiento no responden, más bien, a una estrategia literaria:

Je ne dis rien de Tarragone, de la montagne près de Murviedo, ni du temple de Diane du vieux Sagunte, de son amphithéâtre immense ni de la tour d'Hercule, d'où l'on peut voir les tours de Valence dépasser une forêt de dattiers; ni de la mer, ni du Cabo de Cullera (1905: 15).

En efecto, a menudo Humboldt se sirve de diferentes recursos estilísticos y prácticas intertextuales, tales como digresiones -que sirven para rellenar espacios en la narración y que pueden contener citas (1814: 209) - o remisiones - normalmente en las notas a pie de página-, sin olvidar las continuas alusiones al lector, de quien intenta atraer su atención y conseguir su buena disposición por medio de la captatio benevolentiae: "En suivant l'exemple de ce savant illustre, je crois mériter d'autant moins de reproches, que les événemens que je vais retracer serviront d'appui à la théorie des réactions volcaniques" (1819: 2).

Concluimos este apartado con unas rápidas referencias al receptor de la obra. Este no solo desempeña un importante papel en esta nueva forma de narrar la ciencia, sino también, en el caso que nos ocupa, los problemas con la publicación pueden ser solventados gracias a la extraordinaria acogida del público. De él se espera una actitud reflexiva y participativa, un reconocimiento a la veracidad -reiterada a lo largo del relato- de los hechos y de los testimonios, procedentes de diversas fuentes escrupulosamente mencionadas.

En entrant dans un pays si peu visité, et dont une partie seulement a été décrite par ceux qui l'ont parcouru, j'ai plusieurs motifs pour conserver à mon récit la forme d'un journal. Sous cette forme, le lecteur distinguera plus facilement ce que $\mathrm{j}$ 'ai pu observer par moi-même et ce que je rapporte d'après le témoignage des missionnaires et des indigènes. Il suivra les voyageurs dans leurs occupations journalières; et, appréciant à la fois la brièveté du temps dont ils pouvoient disposer et les difficultés qu'ils avoient à vaincre, il les jugera avec plus d'indulgence (1819: 294).

Si las crónicas de los primeros navegantes estaban impregnadas de color local y de una cierta ingenuidad, con el tiempo el interés científico adquiere, gradualmente, protagonismo favoreciendo, así, la primacía de la descripción sobre la narración. Humboldt teme que este cambio no goce del favor del público, que prefiere "un délassement agréable à une instruction solide" (1814: 31), por lo que intenta adaptar su relato al gusto del lector: 
Il est probable que l'ouvrage que je fais paraître aujourd'hui fixera l'attention d'un plus grand nombre de lecteurs que le détail de mes observations purement scientifiques, ou que mes recherches sur la population, le commerce et les mines de la Nouvelle Espagne (1814: 15).

Los ejemplos en este sentido son numerosísimos -“J'ose rapporter un fait qui n'est pas d'un grand intérêt pour le lecteur" (1819: 513) o "Je fatiguerois le lecteur en continuant l'énumération des merveilles végétales que renferment ces vastes forêts" (1819: 435) -, al igual que las fórmulas "fixer l'attention du lecteur", "ne pas fatiguer le lecteur" o, incluso, “cette remarque sert à fixer plus facilement dans la mémoire du lecteur" (1819: 153). Con todo, y contrariamente a la actitud que adoptan otros viajeros, Humboldt evita dar detalles personales que no sean de utilidad para otros exploradores y que solo resultan atractivos si son moldeados por el talento del escritor:

\begin{abstract}
Il est des détails de la vie commune qu'il peut être utile de consigner dans un itinéraire, parce qu'ils servent à régler la conduite de ceux qui parcourent les mêmes contrées après nous. J'en ai conservé un petit nombre: mais j'ai supprimé la plupart de ces incidens personnels qui n'offrent pas un véritable intérêt de situation, et sur lesquels la perfection du style peut seule répandre de l'agrément (1814: 32).
\end{abstract}

\title{
4. Conclusión
}

En las páginas que preceden nuestro propósito no ha sido otro que acercarnos al proceso de escritura de un viaje único - tanto por su carácter privado, como por su ejecución y resultados-, realizado por un científico excepcional, considerado el precursor de disciplinas como la ecología o la climatología y preocupado durante toda su vida por hacer llegar el conocimiento al mayor número de personas posible. Para ello nos hemos servido de dos fuentes complementarias entre sí, pues hay detalles e informaciones que encuentran su mejor expresión en uno de los dos soportes. Si las cartas, redactadas durante la expedición, constituyen un testimonio cercano sobre la cotidianeidad del viaje, en las que se plasman no solo la incertidumbre acerca de la continuación y término de la exploración, sino también las preocupaciones personales inmediatas, la narración se inscribe en la tradición del relato de viajes científico, esencialmente didáctico y utilitario que, al mismo tiempo, renueva su discurso otorgando al lector un protagonismo del que hasta entones carecía. Su tardía publicación está sobradamente justificada por la calidad y vigencia de la información aportada, pero, sobre todo, porque ofrece una nueva visión de las cosas, que cobran un especial valor interrelacionadas entre sí.

Concluimos con dos pasajes que ilustran a la perfección la figura de Humboldt como escritor de un relato de viajes y como científico excepcional. En las páginas finales del tercer tomo de la Relation historique encontramos una declaración de intenciones del autor en las 
que, fiel a los principios expuestos al comienzo de su relato, y aun a costa de algunas concesiones, expresa su orgullo por ver cumplido su deseo de ofrecer un texto en el que predomina el interés científico:

Dans la publication tardive de ma Relation historique, que j'ai fait précéder d'ouvrages de sciences d'un intérêt circonscrit, j'ai été devancé par des voyageurs qui ont traversé l'Amérique vingt-cinq années après moi. J'ose néanmoins me flatter que tout ce que les pages suivantes offrent de plus essentiel est aussi nouveau aujourd'hui que si je l'avois fait connoître immédiatement après mon retour en Europe. Une telle assertion doit paraître prétentieuse et hardie à ceux qui s'imaginent qu'une région est connue dès qu'elle est traversée, dans tous les sens, par des armées, ou visitée par un grand nombre d'Européens que des spéculations commerciales y ont attirés ; elle paroîtra irréprochable et naturel, si l'on veut se placer sur le terrain que l'auteur de cet ouvrage a choisi de préférence. [...] J'ai supprimé, dans la rédaction de mon journal, tout ce qui a déjà été dit sur l'aspect et la construction des villes, le vêtement des différentes castes, le matériel de la vie commune, et les moyens de transport. Je me suis surtout abstenu de cette polémique qui rend la lecture des voyages si fatigante. Désirant ardemment éviter l'erreur, je ne me suis point occupé des opinions de ceux qui ont écrit sur le même sujet. J'ai désiré conserver à la relation de mon voyage son indépendance de circonstances passagères, et le caractère qui lui est propre, celui d'un ouvrage de science (1825: 547 $548)$.

El segundo fragmento pertenece a su correspondencia. Estas palabras, pronunciadas al término del periplo, reflejan la vitalidad e inquietud científica que le acompañaron durante toda su vida:

Je suis heureusement de retour en Europe après une absence de cinq ans. Il y a deux heures que nous sommes entrés dans la Garonne. La traversée de Philadelphie a été extrêmement heureuse en 27 jours. J'ai quitté Mexico en février et je suis venu de la Havane dans l'Amérique du Nord où le Président du Congrès, Jefferson, m'a comblé de témoignages d'honneur. Mon expédition de 9.000 milles dans les deux hémisphères a été d'un bonheur peut-être sans égal. Je n'ai jamais été malade, et je suis mieux portant, plus fort, plus laborieux, même plus gai que jamais. Je reviens avec trente cinq caisses, et je suis chargé de trésors botaniques, astronomiques et géologiques; il me faudra des années pour publier mon grand ouvrage (1905: 168-169).

\section{Referencias bibliográficas}

Alejandro de Humboldt. Una nueva visión del mundo. 2003. Exposición celebrada en conmemoración al bicentenario de la llegada de Humboldt a México, 25 de septiembre 2003-25 de enero 2004, Antiguo Colegio de San Ildefonso. México. Universidad Nacional Autónoma de México.

Bourguet, Marie-Noëlle. 2003. "El mundo visto desde lo alto del Teide: Alexander von Humboldt en Tenerife" in Montesinos, José, Javier Ordoñez \& Sergio Toledo (eds.). Ciencia y Romanticismo (Symposium 12-14 sept. 2002. Maspalomas, Gran Canaria), La Orotava, Fundación Canaria Orotava de Historia de la Ciencia, 279-301. 
Bourguet, Marie-Noëlle. 2006. "La fabrique du savoir. Essai sur les carnets de voyage d'Alexander von Humboldt" in HiN. Humboldt im Netz. Internationale Zeitschrift für Humboldt-Studien [Revista Internacional de Estudios Humboldtianos], $\mathrm{n}^{\mathrm{o}}$ 13, 17-33. < http:// www.hin-online.de/index.php/hin/article/view/80>

Cioranescu, Alejandro. 1978. Alejandro de Humboldt en Tenerife. Santa Cruz de Tenerife, Aula de cultura de Tenerife.

Eтte, Ottmar. 2015. "Icono-grafía, cali-grafía, auto-grafía. Sobre el arte de la visualización en los diarios del viaje americano de Alexander von Humboldt" in HiN Humboldt im Netz. Internationale Zeitschrift für Humboldt-Studien [Revista Internacional de Estudios Humboldtianos], XVI, n ${ }^{\circ}$ 30, 29-53. < http://www.unipotsdam.de/romanistik/hin/hin30/ette.htm>

G. DE URIARTE, Cristina. 2018. “Algunas consideraciones sobre la función de los prefacios en los relatos franceses de viaje del siglo XIX", in Çédille. Revista de estudios franceses, $\mathrm{n}^{\circ} 14,245-262 .<$ http://cedille.webs.ull.es/14/10uriarte.pdf>

Garrido Moreno, Elisa. 2018. Arte y ciencia en la pintura de paisaje. Alexander von Humboldt. Madrid, Ediciones Doce Calles.

Hamy, Ernest Théodore. 1905. Lettres américaines d'Alexandre de Humboldt (1798-1807). Précédées d'une Notice de J.C. Delamétherie et suivies d'un choix de documents en partie inédits. Publiées avec une introduction et des notes par le Dr E.T. Hamy. Paris, E. Guilmoto.

Holl, Frank (ed.). 2003. Alejandro de Humboldt. Una nueva visión del mundo. México, Universidad Nacional Autónoma de México.

HoLl, Frank. 2003. "Ciencia y arte: Humboldt y los pintores Johann Moritz Rugendas y Ferdinand Bellermann" in HOLL, Frank (ed.). Alejandro de Humboldt. Una nueva visión del mundo. México, Universidad Nacional Autónoma de México, 157-168.

Humboldt, Alexandre de. 1810. Vues des Cordillères et Monumens des peuples indigènes du nouveau continent. Paris, Schoell.

Humboldt, Alexandre de. 1814. Voyage aux régions équinoxiales du Nouveau Continent fait en 1799, 1800, 1801, 1803 et 1804. Paris, Schoell. T. I.

Minguet, Charles (compilación, prólogo, notas y cronología). 1980. Alejandro de Humboldt. Cartas americanas. Caracas, Biblioteca Ayacucho.

Minguet, Charles. 1985. Alejandro de Humboldt historiador y geógrafo de la América española (1799-1804). Jorge PADín Videla (trad.). México, Universidad Nacional Autónoma de México, 2 vol.

PRÜFER LeSKe, Irene. 2014. “El viaje científico canario-americano (1799-1804) de Alexander von Humboldt. Diarios y relaciones epistolares y su recepción en la literatura en el siglo XXI" in XX Coloquio de Historia Canario-Americana (2012). Homenaje a Francisco Morales Padrón. Las Palmas de Gran Canaria, Cabildo de Gran Canaria, 463-472.

Puig-SAmper, Miguel Ángel. 1999. "Humboldt, un prusiano en la Corte del Rey Carlos IV" in Revista de Indias, 59, $\mathrm{n}^{\circ}$ 216, 329-355. < http://revistadeindias.revistas.csic.es/index.php/ revistadeindias/article/view/725/796>

Puig-SAmper, Miguel Ángel \& Sandra REBOK. 2002. “Alexander von Humboldt y el re- 
Anales de Filología Francesa, n. ${ }^{\circ}$ 27, 2019

Cristina G. De URIARTE

lato de su viaje americano redactado en Filadelfia" in Revista de Indias, 62, n ${ }^{\circ} 224,69-84$.

$<$ http://revistadeindias.revistas.csic.es/index.php/revistadeindias/article/view/459>

Puig-SAmper, Miguel Ángel. 2010. "Los relatos de viaje, los diarios y las cartas de Alejandro de Humboldt en vísperas de la Independencia" in Scripta Nova. Revista electrónica de Geografia y Ciencias Sociales, vol. XIV, no 343 (20). < http://revistes.ub.edu/index.php/ ScriptaNova/article/view/1773>

Rocquette, M. (De la). 1865. Humboldt. Correspondance scientifique et littéraire. Paris, Ducrocq. 
